\title{
Risk Assessment Approach to Regulatory Compliance Challenges in Aging Facilities: A Case Study of Harlypet Oil and Gas Nigeria Limited Facilities
}

\author{
C. E. Alaneme*, S. A. Al-Jeshi, S. B. Al-Otaibi \\ Pipelines Distribution \& Terminals Division, Facilities Planning Department, Saudi Aramco, SAUDI ARABIA
}

\begin{abstract}
Compliance with new regulations in old plants remains a recurring challenge because of negative outcome of incidents. This challenge stems from uncertainties in the facilities' integrity, owing to inadequacy of existing integrity-validating technologies. Process facilities deteriorate through cyclic operations, while encroachments from expanding population characteristically raise the risk-levels, leading to need for higher grade materials to meet operational expansions. Retroactive compliance becomes a nightmare with every new regulation without a robust cost-to-benefit assurance. This paper discusses two-phased qualitative and quantitative risk modelling approach through systematic field-data-gathering, hazards identification and analysis by a twelve-man risk management engineers. The methodology successfully computed a "health-check" of the facility's compliance to new regulations, 17 high-risk-hazards were extracted from 42 potential hazards and successfully established varied individual risk levels ranging from 4.07E-06 to 1.64E-04 / year. Also, risks ranged from 1.00E-04 to 5.00E-05/year of tolerable risks to the environment, society, and business were recorded across the facility while, 22 risk-mitigation actions were recommended.
\end{abstract}

Keywords: qualitative risk assessment, quantitative risk assessment, risk management, high consequence area, regulatory compliance, risk levels

\section{INTRODUCTION}

The layout and operation of oil and gas separation facilities, pipeline junctions, and stabilization stations are designed to comply with regulatory safety standards. Incidentally, several of these plants have been operating prior to the promulgation of some new standards that required retroactive compliance. Yet operational exigencies including new fields development, production increment, and other business expansions require installation of additional facilities, even to a point where the existing plants become congested, resulting in what is known as high consequence area (HCA), such as aptly depicted in Fig. 1. Unfortunately, the consequences of noncompliance with statutory health, safety, or environmental requirements, in the event of a major incident, can be catastrophic to an organization. This is as evidenced by the Burnaby oil pipeline rupture in 2007, according to Canadian Broadcasting Corporation News Report [1]. A major accident with significant environmental pollution, fatalities, and even loss of critical contractual obligations in an

\footnotetext{
${ }^{*}$ Corresponding author (Tel:+966 542019317$)$

Email addresses: Charles.alaneme@aramco.com (C. E. Alaneme), salah.jeshi@aramco.com (S. A. Al-Jeshi), salman.otaibi.4@aramco.com (S. B. Al-Otaibi)
}

unsafe facility, could result in considerable damage to an organization's reputation, unsavory cost of endless litigations, and negative perception in the court of public opinion, even to the point of loss of a company's operating license. Yet, the cost and risk of upgrading an operationally aging facility to mitigate the risk of failure often turns to a major investment challenge to operating companies. This paper discusses the deployment of a quantitative risk assessment (QRA) technique for addressing similar challenge in Nigeria, using a functionally expanding Baboon Field Pipeline Manifold (BFPM), belonging to Harlypet Oil and Gas Nigeria Limited (HOG), with sprawling aging facilities as a case study.

\subsection{High Consequence Area}

Resulting impact or consequence of inadvertent release from pipelines or any operating facility vary greatly, and significantly depends on the locale or where the release occurs, as well as the hazardous nature of the product released [2]. The concept of HCA is generally used in pipelines safety regulations to identify specific areas where a release could have the most significant adverse consequence to health, safety, the environment, business, or even the reputation of an organization. Such releases could adversely affect human 


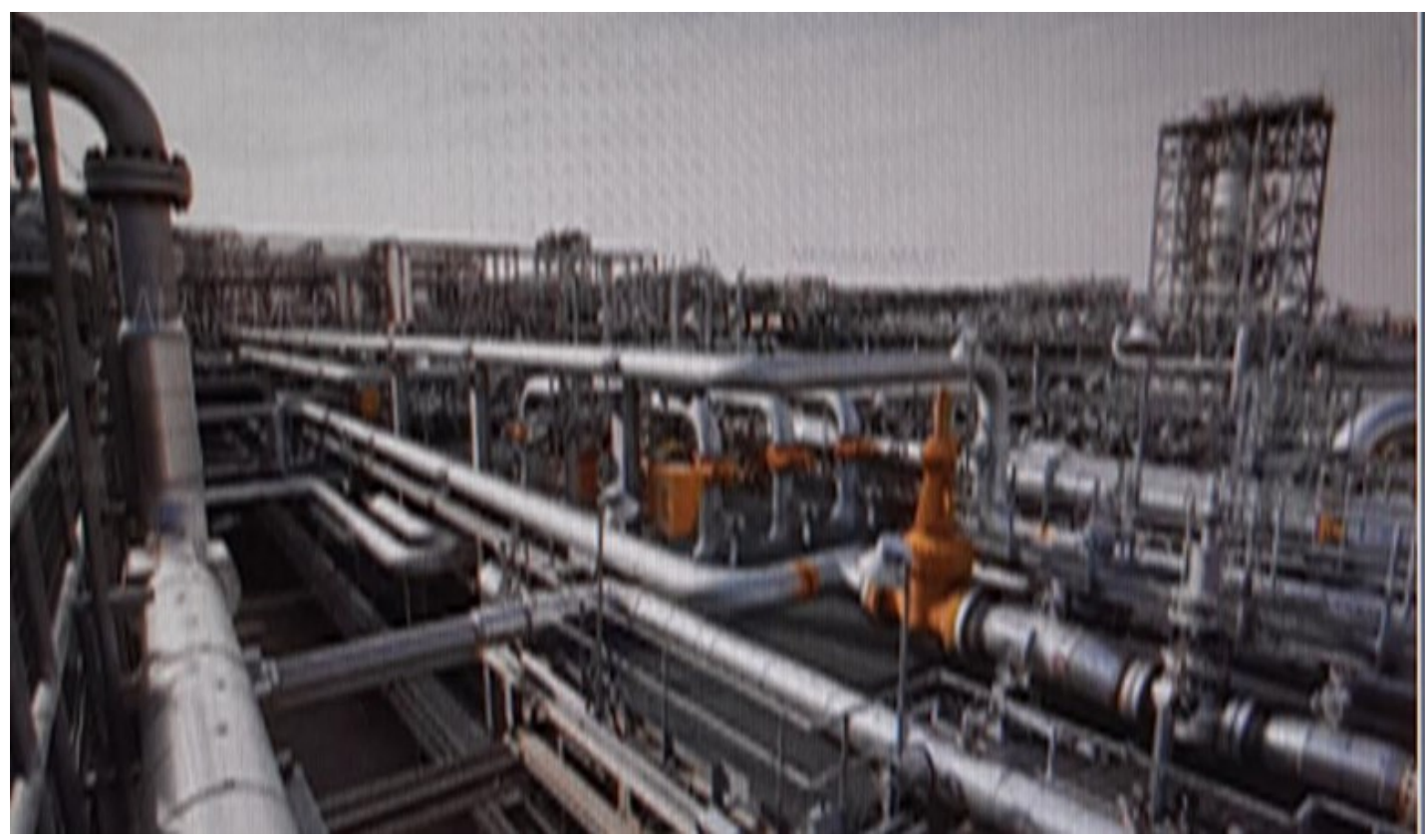

Figure 1: Hazard identification process. Source: Developed by the Study

health and safety, cause environmental degradation, and damage personal or commercial property, and lead to inability to meet contractual obligations. In general, good engineering practices and regulations require operators to take appropriate technical and operational measures, to mitigate the consequence of any pipeline or associated facilities failure in an area with potential high impact.

\subsection{Regulatory Changes}

Regulatory changes meant to improve safety of personnel and environment are always welcome as improvements worth complying with, especially if enacted prior to making an investment decisions for upgrades. Unlike most new operational regulations that are intended for new developments and not to be applied retroactively, safety regulations do require immediate compliance [3]. Often and in this situation, the new regulations rear up conflicts, especially in brownfield developments, where the new facilities will be interfacing with existing ones. This often becomes challenging in already congested plants with little or inadequate room to allow for full compliance with the new regulations. Failing to comply, especially in safety related requirements means incurring penalties and potential legal issues. This is in addition to a full scale impact on health, safety, environment, business, and reputation in the event of an incident or accident.

\subsection{Risk Build Up and Challenges}

Interestingly, a considerable number of oil and gas processing plants worldwide are becoming HCAs with increasing risk impact to third parties and the company business. Some of these plants, like BFPM, were built in remote locations in the 1940 s to 1960 s prior to the promulgation of most environmental, safety, and health regulatory standards. Subsequently, sporadic demographic changes through urban expansion and population encroachments incidentally restrict any further space expansion, and inadvertently reconstituted a previously safe operating facility into a potential risk to people and the environment. This emerging trend now raises not only business, technical, safety, environmental, social, and even legal challenges to most operating companies, but also issues of violation, with ever evolving and increasingly stringent regulations. The integrity of older process facilities naturally deteriorates over time, while some operate under extreme parameters of pressure and temperature in overtly congested and relatively close proximity; some even contain hazardous products. In addition, there is always expansion of facilities or plant modifications within the already constrained space that tend to further stretch the operating systems and spacing, as well as increasing environmental risk. The attendant risks and possible noncompliance with statutory regulations, unwittingly constitute a significant management challenge, especially for responsible hydrocarbon operating companies.

While an in-line instrument (ILI) scraping (pigging) inspection could provide a reliable view of external and internal corrosion conditions of scrapable facilities like pipelines, the corrosion condition of non-scrapable facilities, such as process piping, vessels, shipping facilities; pumps and compressors, and lateral lines; including low pressure and high pressure manifolds are very subjective and relatively unreliable. The spectrum of inspection tools, like nondestructive ultra-sonic testing (NDT UT), available for inspecting such facilities, are restrictively complicated in deployments requiring the expertise of experienced inspectors, which generally reduces the reliability 


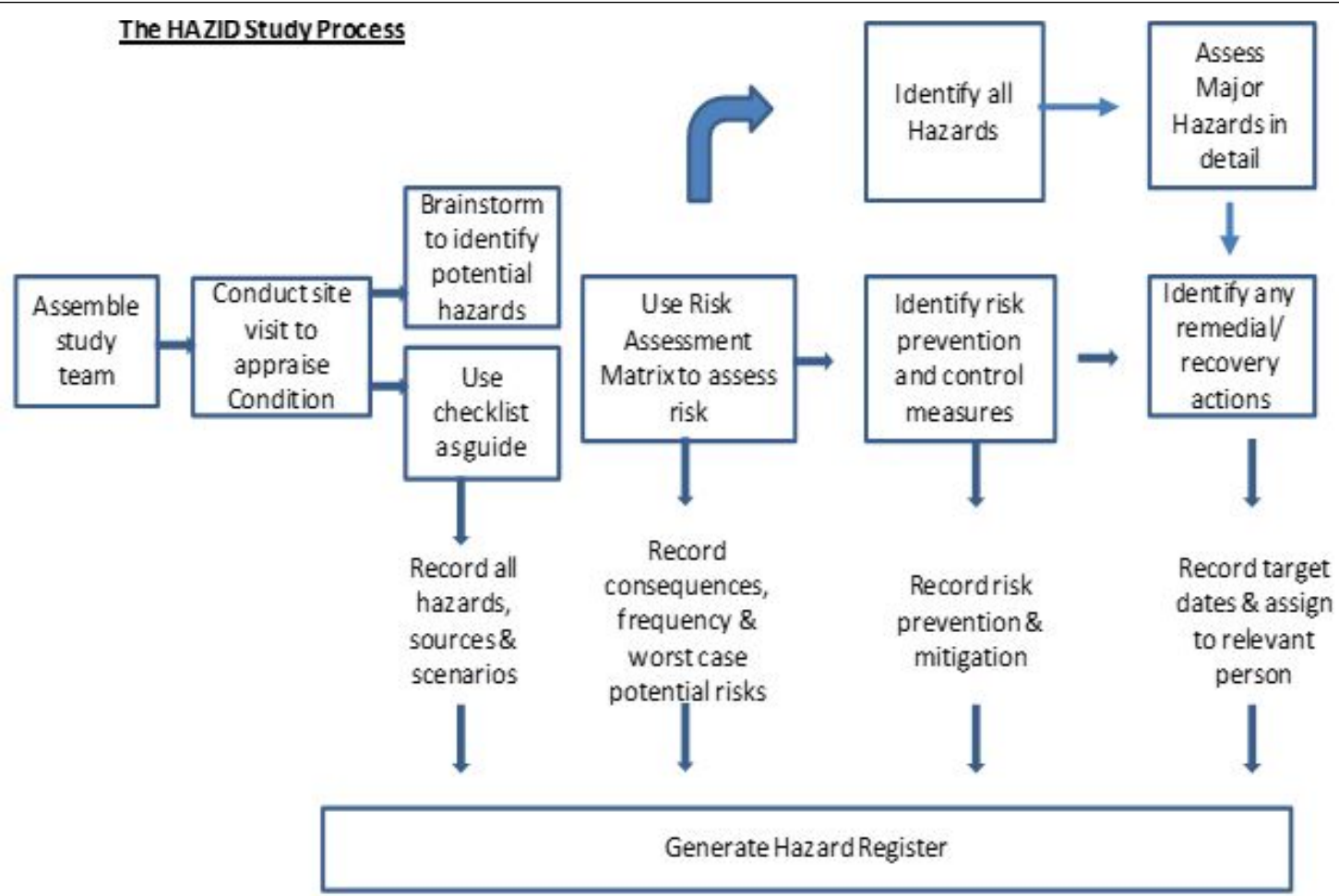

Figure 2: Hazard identification process. Source: Developed by the Study.

of the inspections. The randomness of the UT application (through spot checks) is less assuring with a statistical chance of missing vital vulnerable portions uninspected, thus raising a major risk issue.

\subsection{Risk Development Analysis Approaches}

In developing a risk model for hazard detection and the probable emergency situation in plants, Solodovnikov [4] posited that identification of weakest points is fundamental to speculating potential threats. In different studies on risk management approaches, [5-8] emphasized the need for the use of risk analysis in managing risks. In his seminal works "Unknown Unknown in Project Probabilistic Cost", Raydugui [9] presented an innovative approach to risk management termed unknown unknowns noting that people risk identification requires thinking outside the box. In diverse risk assessment applications, Bastos and Barton [10] applied portfolio theory based on probabilistic methodology, to Brazilian electrical systems, involving development of a standalone hydropower station. Rose [11] provided a detailed treatment of risk assessment and the economic implications for oil field investors, while Kraft [12] discussed risk in policy research; highlighting risk analysis as a veritable tool.

While some risk analyses end in qualitative appraisal as the basis for decision making, others require quantitative evaluation in addition with hazard reduction strategies and cost-benefit analysis [13]. The basic challenge remains to accurately transform the qualitative linguistic expression of risks into quantitative values. Interest- ingly, enormous works such as using fuzzy logic and Monte Carlo simulation for Economics optimization conducted by Alaneme and Igboanugo [14] was undertaken to transform qualitative and linguistic expressions of risk to quantitative numbers for mathematical deployment. Other notable works deploying fuzzy modeling in decision making and subjective workload include [15-17].

In different setting, [18] successfully modeled uncertainty of data in disaster risk assessment, thus proving the reliability of modeling to mimic reality. Other compelling studies on Fuzzy Logic transformation of qualitative reasoning to quantitative numbers and basis for investment decision was successfully implemented in the mining industry [19, 20]. Similarly, [21, 22] proposed the use of QRA to appropriately quantify such risks associated with process activity hazards and accident modelling in process industries, hence the deployment of this approach to assess justifiable spends for retroactive compliance to regulatory changes.

\section{METHODOLOGY}

In this study, a two-phased qualitative and QRA strategy was conducted, primarily to assess the system capacity of the chosen facility and evaluate its compliance with subsisting standards and regulations. The process of the qualitative phase presented in Fig. 2 focused on survey data gathering and systematic brainstorming of hazard identification (HAZID) to identify all health, safety, environment hazards or threats to the company business in the existing controls with emphasis on the design, operation, maintenance, and waste disposal activities. The multidisciplinary HAZID 
Table 1: Risk criticality matrix.

\begin{tabular}{|c|c|c|c|c|c|c|c|}
\hline \multirow{2}{*}{\multicolumn{2}{|c|}{ Frequency }} & \multicolumn{6}{|c|}{ Severity } \\
\hline & & Catastrophic & Critical & Serious & Major & Minor & Negligible \\
\hline Frequent & 5 & 4 & 3 & 2 & 1 & 0 & \\
\hline Probable & 5 & A & A & A & A & B & $\mathrm{C}$ \\
\hline Occasional & 4 & A & A & $\mathrm{A}$ & $\mathrm{B}$ & $\mathrm{C}$ & $\mathrm{C}$ \\
\hline Remote & 3 & A & A & $\mathrm{B}$ & $\mathrm{C}$ & $\mathrm{C}$ & $\mathrm{D}$ \\
\hline Improbable & 2 & A & B & $\mathrm{C}$ & $\mathrm{C}$ & $\mathrm{D}$ & $\mathrm{D}$ \\
\hline Extremely & 1 & $\mathrm{~B}$ & $\mathrm{C}$ & $\mathrm{C}$ & $\mathrm{D}$ & $\mathrm{D}$ & $\mathrm{D}$ \\
\hline Unlikely & 0 & $\mathrm{C}$ & $\mathrm{C}$ & $\mathrm{D}$ & $\mathrm{D}$ & $\mathrm{D}$ & $\mathrm{D}$ \\
\hline
\end{tabular}

Source: An adaptation of Industry Standard Matrix from Harlypet Oil and Gas Nigeria Limited. where: A = Intolerable, $\mathrm{B}=$ Undesirable, $\mathrm{C}=$ Tolerable, and $\mathrm{D}=$ Negligible.

team was drawn from Operations, Maintenance, Inspection Services, Safety, Environmental, Fire Protection, Consulting, and Design departments facilitated by a vendor.

With the aid of the risk criticality matrix in Table 1 , all identified credible residual risks were ranked in terms of frequency and consequence. The risks were inclusive of reduction measures referred to as residual risks. Analysis of the failure mode and effects of the single points of failure demonstrated the criticality of impairing hydrocarbon deliveries, as well as conducting an extensive reliability and availability assessment of both major and minor equipment.

A failure mode and effect analysis (FMEA) was then conducted to provide a systematic assessment of all process equipment and associated electrical and pneumatic systems, and to identify single points of failure that may result in hydrocarbon supply interruption; that is, complete or partial loss of supply, or otherwise impair the plant performance. The failure modes such as failure to close/open on demand, spurious operation or internal/external leakages and the associated rate of failure data were taken from the Offshore Reliability Data (OREDA) Handbook [23]. Similarly, the calculated mean time before failure (MTBF) values assumed a constant failure rate, using the following equation as provided in [23]:

\section{$\operatorname{MBTF}($ years $)=$}

1

failure rate per $\mathrm{hr} \times 8760 \mathrm{hrs} \times$ no. of unit components

In this phase also, a Structural Reliability Assessment (SRA) was conducted to predict corrosion failure frequencies based on existing inspection data and system layout from HOG. functional relation for the probability of failure in Eq. (2) was also extracted from [23] as:

$$
P_{f}=\int_{g(x) \leq 0} f_{x}(X) d x
$$

where, $f=g(X) \leq 0$ represents a failure event with a limit function $g(X)$ and $f_{x}$ is the joint probability density function of the random variables $X$.

In the second phase, the quantitative risk assessment primarily computed the individual and cumulative impact of all the credible loss of containment events using industry standard QRA techniques with emphasis on location specific individual risk (LSIR), individual risk per annum (IRPA), and potential loss of life (PLL). The QRA process systematically identified scenarios leading to loss of containment before defining the numerical consequence or fatalities associated with each hazard. Subsequently, the likelihood of occurrence were assessed and used to establish the numerical levels of the risks.

Given the large number of possible combinations for likely events, the calculations were conducted using a commercially available Phast Risk, Version 6.7, a DNV [24], proprietary software before weighing the risks against HOG risk tolerability criteria in Table 2 . The study successfully modeled jet fires, flash fires, toxic release of $\mathrm{Hy}$ drogen Sulphide, and vapour cloud explosions using the Phast Risk software. The DNV assessment process presented in Fig. 3 was used to generate the Individual Risk contours, F-N curves, and PLL which are intentionally omitted in this paper. Similarly, Eqs. (3) to (9) were extracted from [24] manual to generate the different statistical records for the facility.

The location of risk in a given point is generated from the following relation:

$$
L S R_{i}=\sum_{j} f_{e o, j} \cdot P_{f a t, i, j} \cdot P_{\text {weather }, j} \cdot P_{\text {direction }, i, j}
$$

where $L S R_{i}$ is location specific risk at location $i$, $f_{e o, j}$ is frequency of event outcome $j, P_{f a t, i, j}$ is risk probability at location $i$ due to $j, P_{\text {weather }, j}$ is probability of the weather conditions required to result in the event outcome at $j$ and $P_{\text {direction }, i, j}$ is probability of event outcome being directed at location $i$ and, the relation for computing the location specific individual risk is as follows:

$$
I R_{k}=\theta_{k} \cdot \sum_{i} P_{l o c, i, k} \cdot L S R_{i}
$$

Where $I R_{k}$ is individual risk in a population group $k, \theta_{k}$ is cumulative fraction of time spent by the member in the location of interest and $P_{l o c, i, k}$ is probability that the individual is actually in the location of interest. 
Table 2: Business Risk Tolerability Matrix.

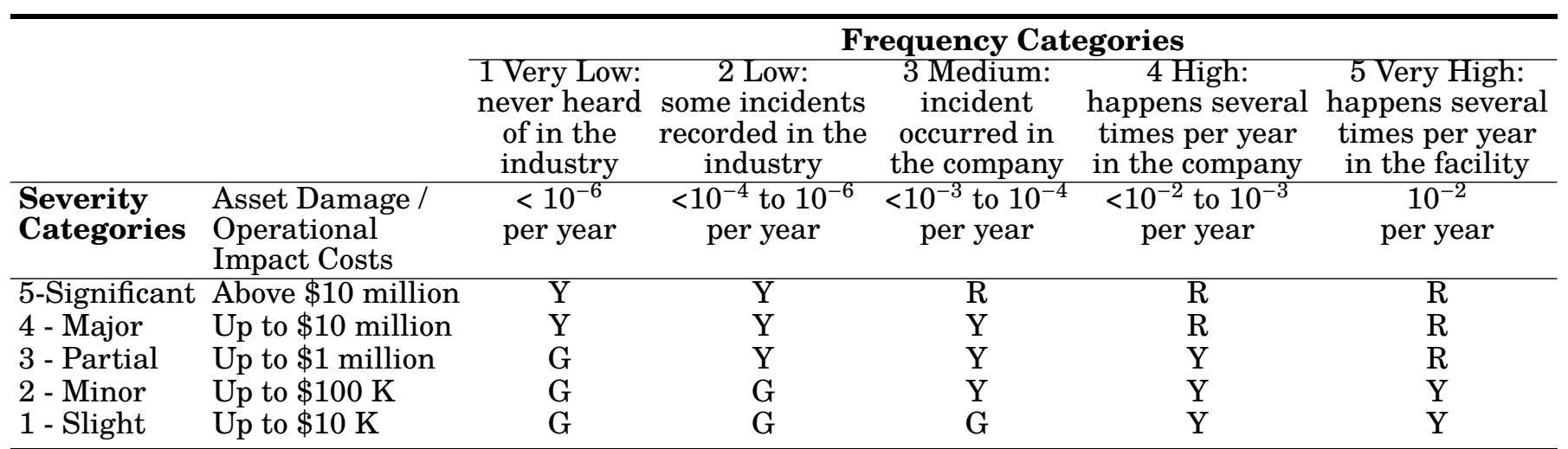

Source: An adaptation of Industry Standard Matrix from Harlypet Oil and Gas Nigeria Limited with approval.

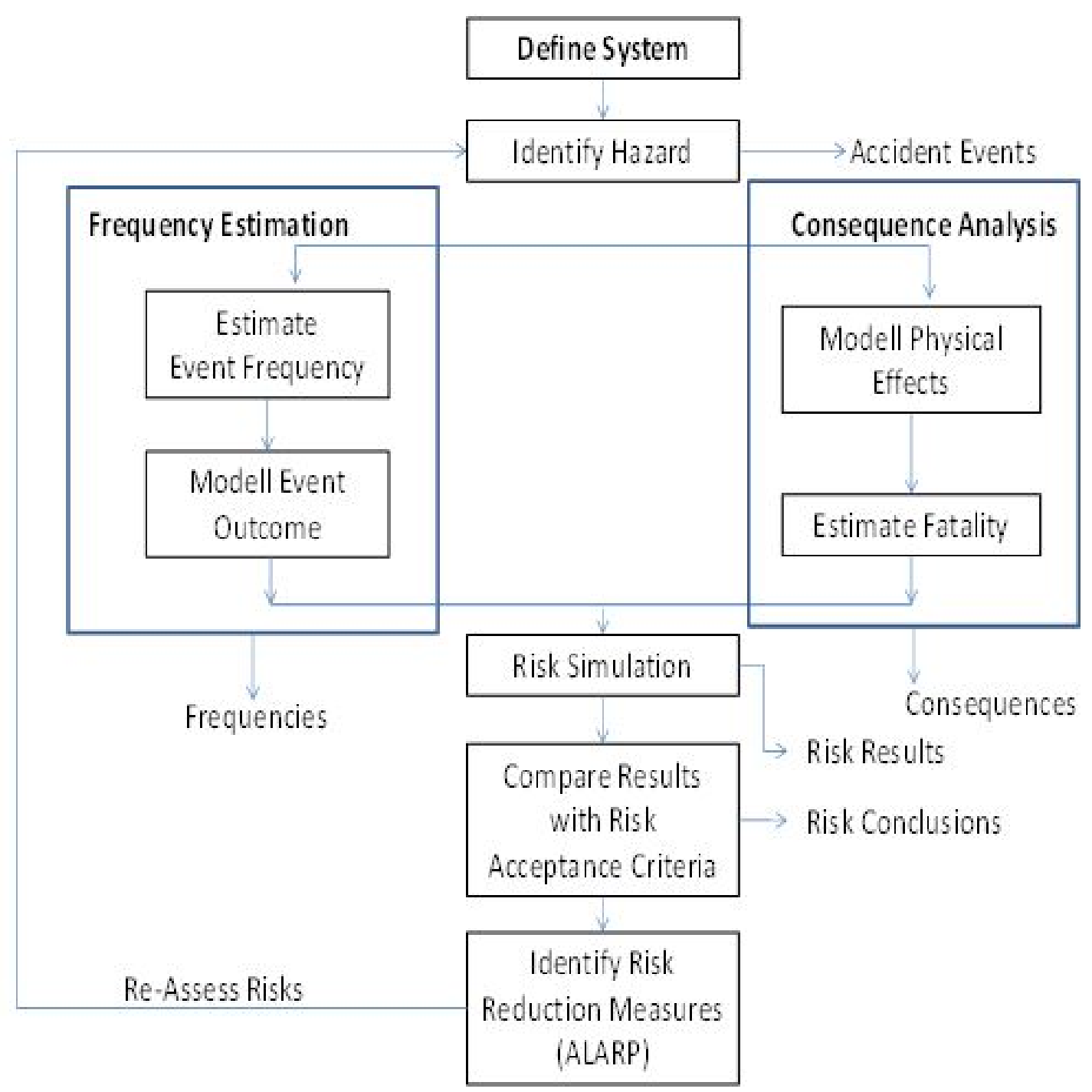

Figure 3: Risk Assessment Process. Source: Det Norske Veritas with approval. 
Therefore, the individual risk at a single location is computed in a single step using Eq. (5) by combining Eqs. (3) and (4), while Eq. (6) provides a simplified methodology for the total location specific individual risk; a summation of all locations and all event outcomes as follows:

$$
I R_{i, j, k}=f_{e o, j} \cdot P_{\text {fat }, i, j} \cdot P_{\text {weather }, j} \cdot P_{\text {direction }, i, j} \cdot P_{l o c, i, k} \cdot \theta_{k}
$$

$$
\begin{aligned}
f_{I R_{i, j, k}=}= & f_{e o, j}+\alpha_{f a t, i, j}+\alpha_{\text {weather }, j} \\
& +\alpha_{\text {direction }, i, j}+\alpha_{\text {loc }, i, k}+\alpha_{\theta_{k}}
\end{aligned}
$$

where $f_{I R_{i, j, k}}$ and $f_{e o, j}$ are Category frequencies for $I R_{i, j, k}$ and $f_{e o, j} . \alpha_{f a t, i, j}, \alpha_{\text {weather }, j}, \alpha_{\text {direction }, i, j}$, $\alpha_{l o c, i, k}$ and $\alpha_{\theta_{k}}$ are the respective probability values.

Subsequently, the annual total individual risk is now generated as:

$$
\begin{aligned}
I R_{t o t, k}= & m_{H, k} \cdot 10^{-7}+m_{G, k} \cdot 10^{-6} \\
& +m_{F, k} \cdot 10^{-5}+m_{E, k} \cdot 10^{-4} \ldots
\end{aligned}
$$

Where: $I R_{t o t, k}$ is total individual risk, $m_{H, k}$ is number of event outcomes in $X$ categories for a given population group $k$.

The PLL, as a factor of individual risk per annum is then expressed for simplicity as:

$$
P L L_{A}=\iint_{\alpha} \operatorname{IRPA}(x, y) m(x, y) d x d y
$$

where $m(x, y)$ is the population density at the location $(x, y)$.

Computed results were then benchmarked with HOG and other similar International [25] and [24] risk acceptance criteria, while potential risk reduction measures to reduce the risks to as low as reasonably practicable (ALARP) were then established with their corresponding cost benefit analysis. The implicit cost of averting a fatality (ICAF) in Eq. (9), is basically a dollar expression per the statistical fatality avoided as follows:

$$
\text { ICAF }=\frac{\text { Net cost of a given option }}{\text { Potential life saving of exposed people }}
$$

The QRA was further expanded to also appraise the risk of business interruption in addition to pruning alternative measures that may improve reliability, and mitigate the business interruption as well as finding the cost-benefit mitigation measures. The tolerability spectrum is guided by the Table 2 matrix.

Consequence Assessment modelling was used by [26] to consider toxic gas dispersion, jet fires, flammable gas dispersion (flash fires), vapor cloud explosions (VCEs), and toxic release events, while the frequency assessment process consists of both "external" derivation of initiating/top event frequencies, using a parts count approach and the generation of scenario/outcome frequencies.

\section{SIMULATION MODELLING PARAMETERS}

The hardware failure rates are obtained from the reliability data given in SINTEF OREDA, [23] where, failures in hardware components are assumed to be independent. At same time, failure distribution function is assumed to be exponential (constant failure rates for all components). The software used to implement vital functions is subject to a rigorous development process and validation and the design is understood to react safely to failures (including software check-redundancy, persistency and plausibility checks). Similarly, the failure mode statistics for the individual components were taken from OREDA [23].

\subsection{Hole Sizes}

The hole sizes and associated leak frequencies shown in Table 3 are extracted from HOG statistical failure records. The record covered a period of over 40-years starting from 1979. The release frequencies calculation and number of potential leak sources for isolatable section included pumps, valves, fittings (flanges and instruments).

\subsection{Meteorological Conditions}

The study assumed an ambient temperature of $26^{\circ} \mathrm{C}$, humidity of $50 \%$, a Pasquill stability $\mathrm{F}$ wind speed of $1.5 \mathrm{~m} / \mathrm{s}$; and a Pasquill stability D wind speed of $5.0 \mathrm{~m} / \mathrm{s}$ based on meteorological data conditions extracted from Fig. 4 to reveal a useable wind direction data in Table 4. Although prediction by air dispersion models vary Jubori [27], extrapolating international values in a dearth of a reliable local data is within acceptable limits given basic postulation that mean wind profile of the neutral class can appropriately approximate that of a strong wind [28].

The study adopted UK HSE's risk tolerability criteria [25] as summarized in Table 5 as bases for assessing acceptability regime of risk to workers and public. A spend of a total 24 hours in a day and 7 days in a week by an individual at the given location is assumed for the LSIR.

On the other hand, HOG provided the business risk criteria presented in Fig. 5. This range is unique to the organization but could be extrapolated to other organizations where a reliable data is not available. Basically, the frequency categories were assigned based on the event frequency, either ignited or un-ignited releases.

\subsection{Equipment Leak Frequencies}

The associated leak frequencies presented in Table 6 were extracted from two primary sources namely the published HSE's Hydrocarbon Release (HCR) database for Process equipment [25] and HOG database for releases frequencies for pipelines and associated scrapers launchers, receivers, and pumps. Coincidentally, the associated leak frequencies have been developed been used for a number of Saudi Aramco studies and rightly deemed appropriate. 
Table 3: Hole Size and Associated Release Frequencies.

\begin{tabular}{|c|c|c|c|c|c|c|}
\hline \multirow{2}{*}{ Equipment } & \multirow{2}{*}{ Total Frequency } & \multicolumn{5}{|c|}{ Frequency Per Hole Size } \\
\hline & & $10 \mathrm{~mm}$ & $25 \mathrm{~mm}$ & $50 \mathrm{~mm}$ & $100 \mathrm{~mm}$ & Full Bore \\
\hline Coolers & $3.62 \mathrm{E}-03$ & $1.90 \mathrm{E}-03$ & $5.94 \mathrm{E}-04$ & $7.13 \mathrm{E}-04$ & $5.94 \mathrm{E}-05$ & $3.56 \mathrm{E}-04$ \\
\hline Compressors, Centrifugal & $1.28 \mathrm{E}-02$ & $1.12 \mathrm{E}-02$ & $1.04 \mathrm{E}-03$ & $2.60 \mathrm{E}-04$ & $1.30 \mathrm{E}-04$ & $1.30 \mathrm{E}-04$ \\
\hline Compressors, Reciprocating & $8.60 \mathrm{E}-02$ & $7.71 \mathrm{E}-02$ & $5.93 \mathrm{E}-03$ & $1.48 \mathrm{E}-03$ & $7.41 \mathrm{E}-04$ & $7.41 \mathrm{E}-04$ \\
\hline Filters & $3.90 \mathrm{E}-03$ & $3.32 \mathrm{E}-03$ & $3.83 \mathrm{E}-04$ & $6.39 \mathrm{E}-05$ & $6.39 \mathrm{E}-05$ & $6.39 \mathrm{E}-05$ \\
\hline Heat Exchangers, HC in Shell & $5.31 \mathrm{E}-03$ & $4.62 \mathrm{E}-03$ & $2.31 \mathrm{E}-04$ & $2.31 \mathrm{E}-04$ & $1.15 \mathrm{E}-04$ & $1.15 \mathrm{E}-04$ \\
\hline Average Gas Pipelines & $3.49 \mathrm{E}-04$ & $1.15 \mathrm{E}-05$ & $8.71 \mathrm{E}-06$ & $3.11 \mathrm{E}-05$ & $2.98 \mathrm{E}-05$ & $4.30 \mathrm{E}-04$ \\
\hline Average Oil Pipelines & $5.41 \mathrm{E}-04$ & $1.78 \mathrm{E}-05$ & $1.35 \mathrm{E}-05$ & $4.80 \mathrm{E}-05$ & $4.66 \mathrm{E}-05$ & $6.67 \mathrm{E}-04$ \\
\hline Average Condensate Pipelines & $5.43 \mathrm{E}-04$ & $1.61 \mathrm{E}-04$ & $1.22 \mathrm{E}-04$ & $1.97 \mathrm{E}-04$ & $2.54 \mathrm{E}-04$ & $1.28 \mathrm{E}-03$ \\
\hline Process Area & $3.20 \mathrm{E}-02$ & $1.09 \mathrm{E}-03$ & $1.95 \mathrm{E}-03$ & $5.43 \mathrm{E}-04$ & $8.91 \mathrm{E}-04$ & $3.65 \mathrm{E}-02$ \\
\hline
\end{tabular}

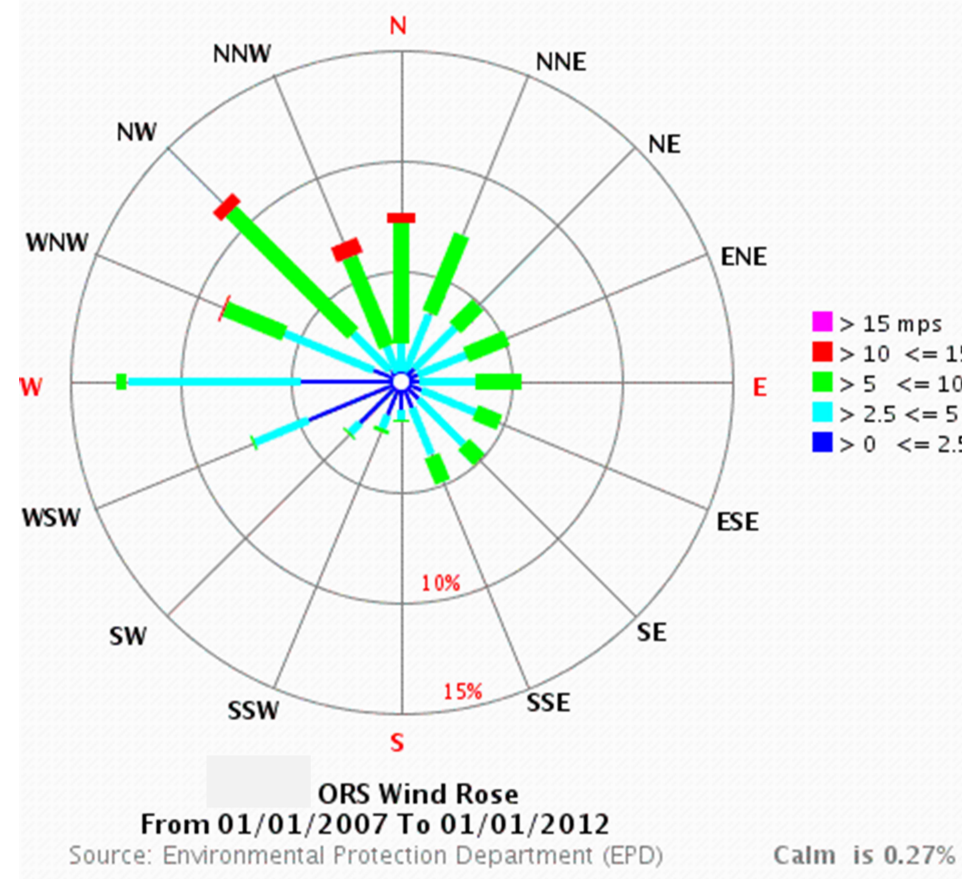

Figure 4: Location area ORS Wind Rose.

Table 4: Prevailing wind directions percentiles.

\begin{tabular}{|c|c|c|c|c|c|c|c|c|c|c|c|c|c|c|c|c|}
\hline \multirow{2}{*}{$\begin{array}{l}\text { Wind Speed } \\
(\mathbf{m} / \mathbf{s})\end{array}$} & \multicolumn{16}{|c|}{ Directions } \\
\hline & $\mathbf{N}$ & NNE & NE & ENE & $\mathbf{E}$ & ESE & SE & SSE & $\mathbf{S}$ & SSW & SW & WSW & W & WNW & NW & NNW \\
\hline $\begin{array}{l}>15.00 \\
>10.00 \text { to } 15.00\end{array}$ & 0.5 & & & & & & & & & & & & & 2 & 6 & \\
\hline 5.00 to 10.00 & 5.6 & 4 & 1.5 & 2.2 & 2 & 1.2 & 1 & 1.4 & 0.1 & 0.2 & 0.2 & 0.2 & 0.5 & 0 & 8.2 & \\
\hline$>2.5$ & 1.4 & 3.2 & 2.9 & ? & 2.9 & 2.8 & 3 & 2.4 & 0.5 & 0.6 & 0.6 & 2.6 & 8 & 4.2 & 2.6 & 1.4 \\
\hline$>0.00 \mathrm{tc}$ & 0.5 & 0.4 & 0.6 & 0 . & 0.8 & 1 & 1 & 1.4 & 2.2 & 4.2 & 4.2 & 1 & & & & \\
\hline Total & 7.5 & 7.2 & 4.9 & 5.2 & 5.5 & 4.6 & 4.8 & 4.8 & 1.6 & 2.2 & 3 & 7 & 12.7 & 8.4 & 11.4 & 6.6 \\
\hline
\end{tabular}

Where $R$ is intolerable, $Y$ is ALARP, and $\mathrm{G}=$ Broadly Acceptable

Table 5: HSE Risk Tolerability Criteria.

\begin{tabular}{lcc}
\hline Tolerability & Workers (Onsite) & Members of Public (Offsite) \\
\hline Intolerable & $\geq 10-3$ per year & $\geq 10-4$ per year \\
Tolerable (subject to ALARP demonstration) & $<10-3$ per year & $<10-4$ per year \\
Broadly acceptable or negligible & $<10-6$ per year & $<10-6$ per year \\
\hline
\end{tabular}




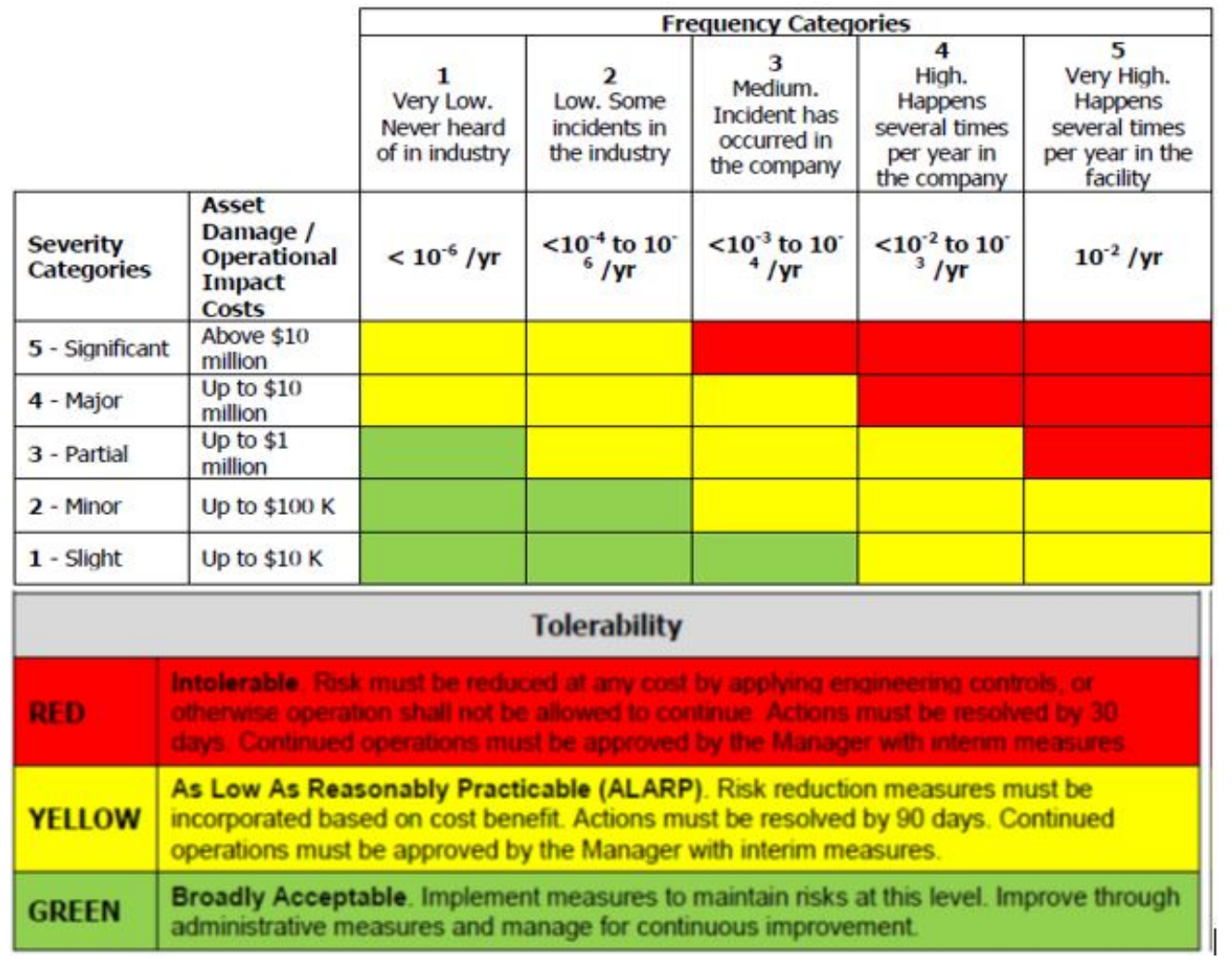

Figure 5: HOG Business Risk Matrix.

Table 6: Ignition Probabilities.

\begin{tabular}{lcc}
\hline Leak & \multicolumn{2}{l}{ Probability of Ignition } \\
& Gas & Liquid \\
\hline Minor $(<1 \mathrm{~kg} / \mathrm{s})$ & 0.01 & 0.01 \\
Major $(1-50 \mathrm{~kg} / \mathrm{s})$ & 0.07 & 0.03 \\
Massive $(>50 \mathrm{~kg} / \mathrm{s})$ & 0.3 & 0.08 \\
\hline
\end{tabular}

\subsection{Ignition Probabilities}

The probability of ignition used for the gas and liquid releases as key input parameters are as presented in Table 7.

The ignition probability assessment adopted the more recent published ignition probability research by Cox, Lees, and Ang [29]. In this study, [29] devised a banding approach that correlated the probability of ignition with the release rates. The variant gas cloud ignition and explosion and immediate ignition probabilities are provided in Table 8 and Table 9 respectively.

\section{RESULTS AND DISCUSSION}

Principally, this risk assessment extricated a characteristic spectrum of flash and jet fires dominated risks coming from the mainly flammable gas streams. It established varied individual risk levels with overall PLL ranging from 4.07E-06 to $1.64 \mathrm{E}-04$ /year, while the level of risk (LSIR) across the site ranged from an insignificant $1.00 \mathrm{E}-04$ to 5.00E-05 per year that falls within the lower region of company and UK tolerable risks. Apart from generating varying degrees of societal impact, it was also able to sift out each work group incremental risk attributable to working in the plant alone.

Specifically, the IRPA for three different category of workers assigned to routine general operations in the facility and as presented in Table 10 showed that the assessed workers experienced IRPA levels within the lower part of the tolerable region. Further review showed that IRPA is sensitive to the occupancy levels and the total working hours per year. However, this is not a true representation of the overall risk levels experienced by these workers given that, every worker is also exposes to hazards from other facilities.

On the other hand, the group risk expressed in terms of a PLL predicted the number of fatalities per year in the event of an uncontrolled major release. Based on the total number of workers (exposed to the overall risks) from the manning data, the PLL for all worker groups within the manifold Junction have been calculated and is presented in Table 11.

Societal Risk showed no significant risk as the shortest distance to the nearest residential area is about 1.4 kilometers. comparatively, a significant impact to society is not expected. The overall business risk assessment understandably identified redundancy levels for critical facilities, and the sufficiency of separation distances in addition to the degrees of escalated or "domino" escalation risks in noncritical equipment. Unlike the ignited releases showed an acceptable risk level, a sum- 
Table 7: Gas Cloud Ignition and Explosion Probabilities.

\begin{tabular}{lccc}
\hline Leak & $\begin{array}{c}\text { Total Probability } \\
\text { of Ignition (Gas) }\end{array}$ & $\begin{array}{c}\text { Probability of Explosion } \\
\text { Given Ignition }\end{array}$ & $\begin{array}{c}\text { Probability of Explosion } \\
\text { Given Leak } \\
\text { C=A X B }\end{array}$ \\
Minor $(<1 \mathrm{~kg} / \mathrm{s})$ & 0.01 & 0.04 & 0.0004 \\
Major $(1-50 \mathrm{~kg} / \mathrm{s})$ & 0.07 & 0.12 & 0.008 \\
Massive $(>50 \mathrm{~kg} / \mathrm{s})$ & 0.3 & 0.3 & 0.09 \\
\hline
\end{tabular}

Table 8: Immediate Ignition Probability.

\begin{tabular}{lccc}
\hline & $\begin{array}{c}\text { Total Ignitions } \\
\text { "Probability of } \\
\text { Ignition (Gas)" }\end{array}$ & $\begin{array}{c}\text { Delayed Ignitions } \\
\text { "Probability of Explosion } \\
\text { Given Leak" }\end{array}$ & $\begin{array}{c}\text { Immediate Ignition } \\
\text { Probability }\end{array}$ \\
& $\mathrm{A}$ & $\mathrm{C}$ & $\mathrm{D}=\mathrm{A}-\mathrm{C}$ \\
\hline Minor $(<1 \mathrm{~kg} / \mathrm{s})$ & 0.0012 & 0.00024 & 0.00096 \\
Major $(1-50 \mathrm{~kg} / \mathrm{s})$ & 0.008 & 0.0016 & 0.0064 \\
Massive $(>50 \mathrm{~kg} / \mathrm{s})$ & 0.3 & 0.06 & 0.24 \\
\hline
\end{tabular}

Table 9: Summary of IRPA Results.

\begin{tabular}{lc}
\hline Worker Group & IRPA (yr) \\
\hline General Maintenance Personnel & $2.04 \mathrm{E}-06$ \\
Scraping or Pigging Operation Personnel & $4.09 \mathrm{E}-06$ \\
Cleaning and Filter Replacement Personnel & $1.09 \mathrm{E}-05$ \\
\hline
\end{tabular}

Table 10: Summary of PLL Results.

\begin{tabular}{lc}
\hline Worker Group & IRPA (yr) \\
\hline General Maintenance Personnel & $4.07 \mathrm{E}-06$ \\
Scraping or Pigging Operation Personnel & $2.45 \mathrm{E}-05$ \\
Cleaning and Filter Replacement Personnel & $1.64 \mathrm{E}-04$ \\
\hline
\end{tabular}

Table 11: Summary Representation of Un-Ignited Release Costs*.

\begin{tabular}{|c|c|c|c|c|c|}
\hline $\begin{array}{l}\text { Isolation } \\
\text { Section }\end{array}$ & $\begin{array}{l}\text { Release } \\
\text { Size }\end{array}$ & $\underset{(\$)}{\text { Release Cost }}$ & Total Loss of Sales & $\begin{array}{l}\text { Total Loss (Inventory } \\
\text { + Sales Downtime }(\$)\end{array}$ & $\begin{array}{l}\text { Distribution Cost } \\
\text { (Credible Loss) }(\$)\end{array}$ \\
\hline \multirow{5}{*}{ Gas Line } & $10 \mathrm{~mm}$ & 382 & 90,563 & 90,945 & 73,777 \\
\hline & $25 \mathrm{~mm}$ & 1,970 & 90,563 & 92,532 & 2,473 \\
\hline & $50 \mathrm{~mm}$ & 7,638 & 90,563 & 98,201 & 1,988 \\
\hline & $100 \mathrm{~mm}$ & 30,313 & $8,150,625$ & $8,180,647$ & 591,399 \\
\hline & FB & 421,022 & $8,150,625$ & $8,571,647$ & 593,742 \\
\hline \multirow[b]{2}{*}{$\begin{array}{l}\text { Isolation } \\
\text { Section }\end{array}$} & & Total D & istribution Cost & & $1,263,379$ \\
\hline & $\begin{array}{l}\text { Release } \\
\text { Size }\end{array}$ & $\underset{(\$)}{\text { Release Cost }}$ & $\underset{(\$)}{\text { Total Loss of Sales }}$ & $\begin{array}{l}\text { Total Loss (Inventory } \\
\text { + Sales Downtime }(\$)\end{array}$ & $\begin{array}{l}\text { Distribution Cost } \\
\text { (Credible Loss) }(\$)\end{array}$ \\
\hline \multirow{5}{*}{ Oil Line } & $10 \mathrm{~mm}$ & 277 & 272,550 & 272,827 & 173,515 \\
\hline & $25 \mathrm{~mm}$ & 985 & 272,550 & 273,535 & 3,058 \\
\hline & $50 \mathrm{~mm}$ & 3,513 & 272,550 & 276,063 & 3,087 \\
\hline & $100 \mathrm{~mm}$ & 13,625 & $24,529,500$ & $24,543,126$ & 274,418 \\
\hline & FB & 148,642 & $24,529,500$ & $24,529,500$ & $8,630,663$ \\
\hline \multirow[t]{2}{*}{$\begin{array}{l}\text { Isolation } \\
\text { Section }\end{array}$} & $\begin{array}{l}\text { Release } \\
\text { Size }\end{array}$ & $\begin{array}{r}\text { Total D } \\
\text { Release Cost } \\
(\$)\end{array}$ & $\begin{array}{l}\text { istribution Cost } \\
\text { Total Loss of Sales } \\
(\$)\end{array}$ & $\begin{array}{l}\text { Total Loss (Inventory } \\
\text { + Sales Downtime }(\$)\end{array}$ & $\begin{array}{c}\text { 8,630,663 } \\
\text { Distribution Cost } \\
\text { (Credible Loss) }(\$)\end{array}$ \\
\hline & $10 \mathrm{~mm}$ & 129 & 215,625 & 215,754 & 183,911 \\
\hline \multirow{2}{*}{ Associated } & $25 \mathrm{~mm}$ & 646 & 215,625 & 216,271 & 21,622 \\
\hline & $50 \mathrm{~mm}$ & 2,492 & 215,625 & 218,117 & 6,552 \\
\hline \multirow[t]{3}{*}{ Facility } & $100 \mathrm{~mm}$ & 9,877 & $19,406,250$ & $19,416,127$ & 167,266 \\
\hline & FB & 137,121 & $19,406,250$ & $19,543,371$ & 180,990 \\
\hline & \multicolumn{4}{|c|}{ Total Distribution Cost } & 560,342 \\
\hline
\end{tabular}

*The listed facilities are representative of all the different facilities in the Manifold 
Table 12: Refined Primary Failure Frequency.

\begin{tabular}{|c|c|c|c|c|c|}
\hline $\begin{array}{l}\text { External } \\
\text { Interference }\end{array}$ & $\begin{array}{c}\text { Construction } \\
\text { Defect/Material Failure }\end{array}$ & Corrosion & Ground Movement & $\begin{array}{c}\text { Hot-Tap Made } \\
\text { by Error }\end{array}$ & $\begin{array}{l}\text { Others \& } \\
\text { Unknown }\end{array}$ \\
\hline $1.61-\mathrm{E}-07$ & $6.44 \mathrm{E}-08$ & $6.01 \mathrm{E} 08$ & $0.00 \mathrm{E}+00$ & $0.00 \mathrm{E}+00$ & $2.61 \mathrm{E}-08$ \\
\hline
\end{tabular}

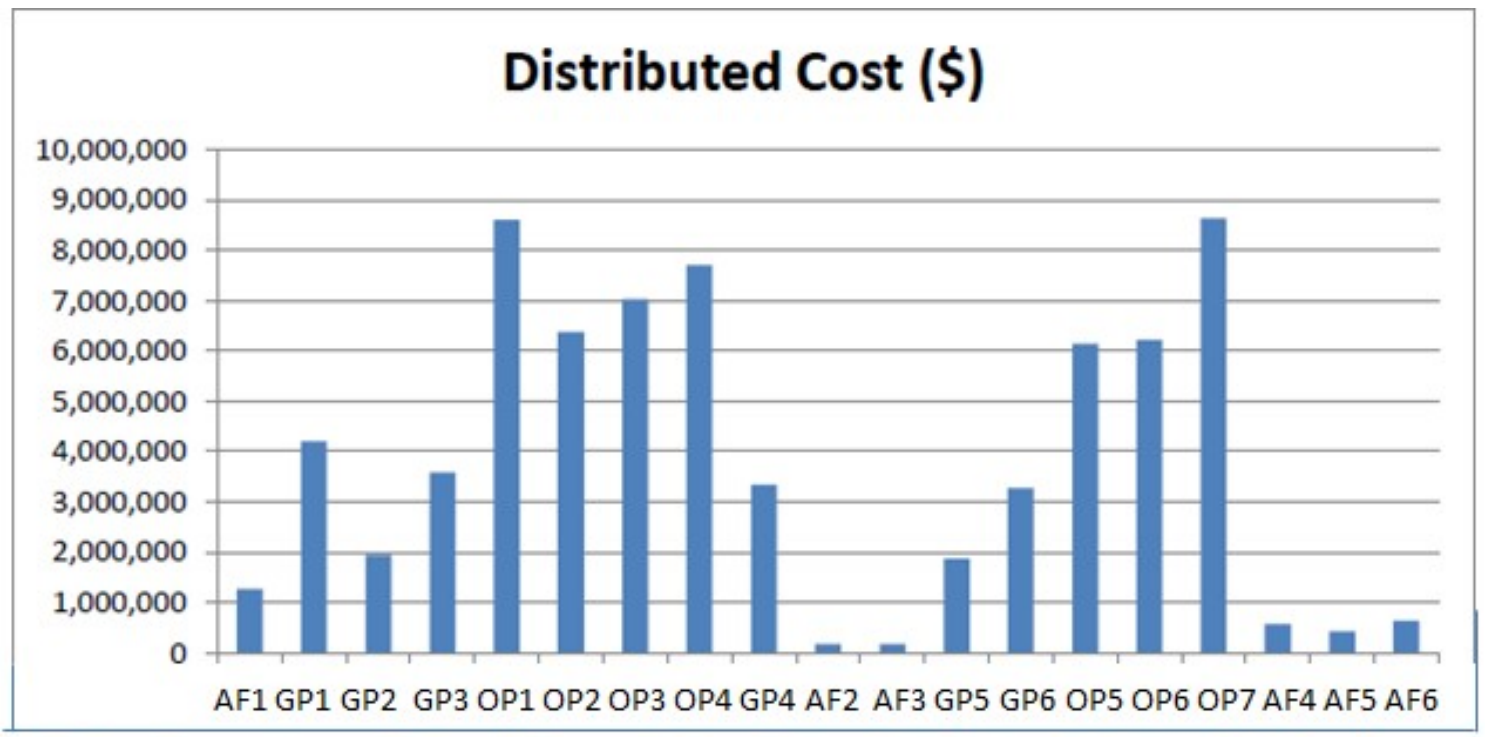

AF-Associated Facilities, GP-Gas Pipeline, OP - Oil Pipeline

Figure 6: Distributed Cost (US\$).

mary of un-ignited release costs for loss of hydrocarbon gas and oil transporting pipelines and the associated facilities are respectively presented in Table 12.

The distributed costs columns shows the costs associated with loss of sales as a result of the facilities downtime with no redundancy. A general costs distribution for the different facilities in the Plant, are presented in Fig. 6.

The resulting primary failure frequencies and contributions based on data adjustments are presented in Table 13 and Fig. 7. Therefore, the calculated refined primary failure frequency of 3.11E-07 per year showed a good health check of the plant, with a $20 \%$ reduction from the original frequency, deduced from the European Gas Pipeline Incident Data Group [30] data collected and reported since 1970 .

Effectively, external interference with $41 \%$ contribution presents the greatest threat to the plant and facilities with defect materials and corrosion posting a distant $17 \%$ and $15 \%$ respectively, while hot taps and seismic activities remain insignificant.

A further analysis posited that pipelines and other facilities with smaller diameters are more vulnerable to external interference due to their relatively thinner walls. This demonstrated that having larger diameter or thicker pipe walls is an effective measure against external interference. In addition, smaller pipelines or facilities with thinner walls are more susceptible to corrosion

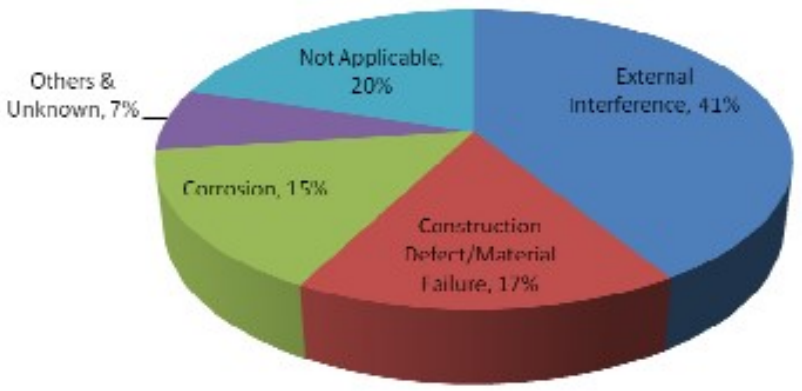

Figure 7: Frequency data adjustment contributing factors.

while thicker walled facilities take a longer time, before causing an incident with more chances for the corrosion to be detected before failure.

\section{CONCLUSION AND RECOMMENDATIONS}

The health condition of the BFPM under this case study has been established with an auditable track of all actual residual hazards associated with the design, operation, and maintenance of the BFPM. Principally, the level of risk across the site ranges from $1.00 \mathrm{E}-04$ per year to $5.00 \mathrm{E}-05$ per year. All assessed worker experience individual risk levels within the tolerable region. In addition, the overall PLL ranged from 4.07E-06 to $1.64 \mathrm{E}-04$ per year. As a result, all hazards with the potential to result in health, safety, environmental, and business risks were effectively fac- 
Table 13: Refined primary failure frequency.

\begin{tabular}{lccccc}
\hline $\begin{array}{l}\text { External } \\
\text { Interference }\end{array}$ & $\begin{array}{c}\text { Construction Defect Corrosion } \\
\text { /Material Failure }\end{array}$ & $\begin{array}{c}\text { Ground } \\
\text { Movement }\end{array}$ & $\begin{array}{c}\text { Hot-Tap } \\
\text { Made by Error }\end{array}$ & Others \& Unknown \\
\hline $1.61-\mathrm{E}-07$ & $6.44 \mathrm{E}-08$ & $6.01 \mathrm{E} 08$ & $0.00 \mathrm{E}+00$ & $0.00 \mathrm{E}+00$ & $2.61 \mathrm{E}-08$ \\
\hline
\end{tabular}

tored in the risk management radar with appropriate risk reduction measures put in place. Indicatively, a significant impact on society is not expected. Knowing the risk level and the dominating sources of threat and impacts to the safe operation of the plant has become a stepping stone in the effective control and management of risk. On the business risk, the study established significant redundancy of supply and that the majority of ignited release scenarios resulted in no escalation no any impairment of non-critical equipment. However, no scenario with intolerable business risk.

Knowing the above presents a basis for resolving the conflict between noncompliance with statutory regulations and legacy (i.e., old) equipment, which poses decision challenge on deploying lateral applicability of prevailing regulations or avoidance of retroactive applicability. Also, the study successfully addressed issues with perceived insufficient separation distances of operating facilities and concerns on integrity assurance. Although the existence of a number of credible escalation scenarios with the potential to cause total facility shutdown are factored in, hot works and ground movement, such as seismic activities seem insignificant due to HOG experience and location. Other organizations that face greater risks in this area should incorporate them in their general risk analysis/assessments.

Irrespective of the timeline of each regulation, a due risk assessment and compliance evaluation is suggested for every plant/facility. Operating a facility without fully assessing the risks can threaten a company's reputation and makes a disaster more likely. The option to redesign, relocate, or reduce system operating conditions to within safety limits should be given a higher priority, so that facilities are operated according to regulatory standards and procedures.

\section{Acknowledgement}

The authors wish to acknowledge and appreciate Harlypet Oil and Gas Limited for permitting the use of their company's facilities and records for this research work.

\section{References}

[1] Canadian Broadcasting Corporation, "Transportation Safety Board report on Burnaby oil spill of March 2009," http://www.cbc.ca/news/canada/britishcolumbia/story/2009/03/18/bc-burnaby-pipeline.html, October 2020, news Report.

[2] U.S. Department of Transportation, "Pipeline \& hazardous materials safety administration."

[3] T. Lin, "Compliance, technology, and modern finance," Journal of Corporate, Financial \& Commercial Law, vol. 2, no. 1, pp. 161-182, 2016.
[4] A. Solodovnikov and R. Tlyasheva. (2007) Fabrication system hazard detection in oil and gas processing plants, oil and gas business. [Online]. Available: http://www.ogbus.ru/eng/

[5] S. Ward and C. Chapman, "Extending the use of risk analysis in project management," International Journal of Project Management, vol. 9, no. 2, pp. 117-123, 1991.

[6] J. Harbaugh, J. Davis, and J. Wendebourg, "Computing risk for oil prospects: Principles and programs," Elsevier Science, vol. 13, no. 7, p. 852, 1996.

[7] C. Undram and S. Takakuwa, "Using simulation analysis for mining risk management project," in Proceedings of the 2009 Winter Simulation Conference, January 2009 .

[8] S. Andersen and B. Mostue, "Risk analysis and risk management approaches applied to the petroleum industry and their applicability to io concepts," Safety Science, vol. 50, no. 10, pp. 2010-2019, 2011.

[9] Y. Raydugin, "Unknown unknown in project probabilistic cost and schedule risk models," Palisade White Papers, 2011.

[10] P. Bastos and E. Bortoni, "Portfolio analysis applied to small hydroelectric plant investment," in IEE Journal, 8th International Conference on Probabilistic Methods Applied to Power Systems, Iowa, September 2004, pp. $12-16$.

[11] P. Rose, "Risk analysis and management of petroleum exploration ventures. aapg methods in exploration," American Association of Peytroleum Geologists, 2012, tulsa USA.

[12] M. Kraft, "The use of risk analysis in federal regulatory agencies: An exploration. review of policy research," Policy Studies Organization, vol. 1, no. 4, pp. 666-675, 1982.

[13] J. Alderman and W. Fink. (2013, Januray) Risk assessment in the oil and gas energy industry, fire protection engineering. Society of Fire Protection Engineers. [Online]. Available: http://www.fpemag. com/archives/article.asp?issue_id $=43 \& \mathrm{i}=316$

[14] C. Alaneme and A. Igboanugo, "Managing Marginal Oilfield Risks with Fuzzy Logic and Monte Carlo Simulation for Economics Optimization," Journal of Emerging Trends in Engineering and Applied Sciences, vol. 3, no. 4 , pp. $660-667,2012$.

[15] G. Svenda, S. Kanjuh, T. Konjic, and V. Miranda, "Using a fuzzy modeling in decision making for planning under uncertainty with risk analysis paradigm," in IEEE Publication, November 2020, pp. 12-16, http://www.ewh.ieee.org/reg/8/conferences.html.

[16] M. Kumar, D. Arndt, S. Kreuzfeld, K. Thurow, N. Stoll, and R. Stoll, "Fuzzy techniques for subjective workloadscore modeling under uncertainties," Systems, man, and cybernetics, vol. 38, no. 6, pp. 1449-1463, 2008.

[17] L. Jian-wei and L. Zhonghua, "Research on dynamic evolvement analysis and modeling of risk in development of navy vessel," Institute of Science, Naval University of Engineering Wuhan, IEEE Journal, vol. 1, no. 4, pp. 1-4, 2008.

[18] Y.Xue, C. Huang, and X. Huang, "A new method and its application of handling fuzzy uncertainty of data in disaster risk assessment," IEEE Computer Society Washington Publication, vol. 1, no. 5, pp. 421-425, 2009.

[19] Z. Guo and Q. Zhang, "A new approach to project risk evaluation based on intuitionistic fuzzy sets," International conference on Fuzzy systems and knowledge discovery Proceedings, vol. 6, no. 3, pp. 58-61, 2009.

[20] Q. Cao, J. Ruan, and K. Liu, "Fuzzy evaluation on mining investment decision based on membership degree transformation new algorithm," in ISECS International Colloquium on Computing, Communication, 
Control, and Management, IEEE Journal, 2009, pp. 24-28.

[21] M. Kalantarnia, F. Khan, and K. Hawboldt, "Dynamic risk assessment using failure assessment and bayesian theory," Journal of Loss Prevention in the Process Industries, vol. 22 , no. 5, pp. 600-606, 2009.

[22] A. Al-shanini, A. Ahmad, and F. Khan, "Accident modelling and analysis in process industries," Journal of Loss Prevention in The Process Industries, vol. 32, no. 6, pp. 319-334, 2014.

[23] SINTEF OREDA, “Offshore and onshore reliability data handbook," 6th Edition, 2015 SINTEF Technology and Society, 2015, norges teknisk-naturvitenskapelige universitet.

[24] Det Norske Veritas, "Risk acceptance criteria and risk based damage stability, European Maritime Safety Agency, Norway, Report No.: 2015-0165, Rev. 1, 2015, dNV GL AS Maritime Advisory BDL New building.

[25] J. Spouge, "Health safety executives,"Hydrocarbon Release Statistics 2010, 2020, http://www.hse.gov.uk/hcr3.

[26] A. Chakrabarty, S. Mannan, and T. Cagin, "Multiscale modeling for process safety applications, butterworthheinemann," Elsevier, vol. 32, no. 2, pp. 309-338, 2016.

[27] M. Al-Jubori, "Atmospheric modelling," Faculty of Bioscience Engineering, 2016.

[28] N. Keigo, Y. Toru, O. Ryozo, K. Hideki, and S. Hirofumi, "Observational assessment of applicability of pasquill stability class in urban areas for detection of neutrally stratified wind profiles," Journal of Wind Engineering and Industrial Aerodynamics, vol. 206, no. 6, pp. 83-93, 2020.

[29] A. Cox, F. Lees, and M. Ang, "Classification of hazardous locations," The Institution of Chemical Engineers, Rugby, UK, 1990.

[30] "European gas pipeline incident data group," 7th Report of the European Gas Pipeline Incident Data Group, 2008, doc. No. EGIG 08 TV-B.0502 1970-2007. 